\title{
Human immunodeficiency virus and the gastrointestinal immune system: does highly active antiretroviral therapy restore gut immunity?
}

\author{
CT Costiniuk ${ }^{1,2}$ and JB Angel ${ }^{1,2,3}$
}

While only partial immune reconstitution in gut-associated lymphoid tissue typically occurs following initiation of highly active antiretroviral therapy (HAART) in human immunodeficiency virus (HIV) infection, near-complete immune reconstitution has occasionally been described. This review highlights findings from studies examining the effects of HAART and the timing of its initiation on gastrointestinal (GI) CD4 + T-cell recovery. Its effects on specific CD4 + T-cell subtypes, CD8 + T cells, natural killer cells, and immunoglobulins are also described. Finally, the ability of HAART to restore the intestinal epithelial barrier and lymphatic tissue architecture and reduce microbial translocation is addressed. Determining whether HAART has the ability to prevent permanent GI immune damage when commenced in acute HIV infection has implications for the optimal timing of HAART initiation.

\section{INTRODUCTION}

Gut-associated lymphoid tissue (GALT) is a well-described site of human immunodeficiency virus (HIV) persistence. ${ }^{1,2}$ Although gastrointestinal (GI) immune defences are key players in modulating the pathogenic effects of $\mathrm{HIV}^{3}$ the GI tract has been shown to be depleted of CD4 $+\mathrm{T}$ cells at all stages of HIV infection, ${ }^{4}$ and this has been attributed in part to HIV's propensity for infecting activated memory $\mathrm{T}$ cells expressing CCR5 chemokine receptors, which are plentiful in the GI tract., ${ }^{4,5}$ Studies in macaques have revealed that $~ 90 \%$ of GALT CD $4+$ $\mathrm{T}$ cells are depleted within 2 weeks of simian immunodeficiency virus acquisition, ${ }^{6}$ which is in clear contrast to the more gradual rate of $\mathrm{CD} 4+$ decline usually observed in peripheral blood. Although it is well-established that viral suppression with highly active antiretroviral therapy (HAART) leads to immune restoration in the periphery, an ongoing issue of contention, given the distinct differences between these compartments, is whether HAART can restore GI immunity.

Initial studies examining the effects of HAART on GI immunity focused predominantly on individuals with chronic HIV infection. In more recent years, emphasis has been placed on studying GI immune reconstitution with HAART in acute infection. This heightened interest stems from the hope of abrogating damage to the GI immune system before it becomes irreparable. This review focuses on the recovery of CD $4+\mathrm{T}$ cells and other aspects of GI immunity after HAART initiation in the setting of chronic, as well as acute and primary, HIV infection.

\section{THE GI IMMUNE SYSTEM}

As reviewed by Cheroutre and Madakamutil, ${ }^{7}$ GALT consists of mesenteric lymph nodes, Peyer's patches in the small intestine and follicular aggregates in the large intestines, appendix, and cecum. Lamina propria lymphocytes and intraepithelial lymphocytes are also contained within GALT. From a functional perspective, immune cells within the GI tract are located in immune-inductive and immune-effector sites. ${ }^{7}$

After antigens are endocytosed by M (microfold) cells in the intestinal lumen, they are transported to inductive sites including the Peyer's patches within the small intestines, lymphoid aggregates within the large intestines, and mesenteric lymph nodes within both the large and small intestines. Peyer's patches are located in the mucosa and submucosa. Maturation of naive $T$ cells occurs within mesenteric lymph nodes and other secondary lymphoid organs that drain the GI mucosal tissue. Here they are primed to express GI-specific homing markers, promoting their entry into systemic circulation where they

\footnotetext{
${ }^{1}$ Division of Infectious Diseases, Department of Medicine, Ottawa Hospital, Ottawa, Canada. ${ }^{2}$ Department of Biochemistry, Microbiology and Immunology, University of Ottawa, Ottawa, Canada. ${ }^{3}$ Ottawa Hospital Research Institute, Ottawa, Canada. Correspondence: JB Angel (jangel@ohri.ca) or CT Costiniuk (ccostiniuk@ottawahospital.on.ca)

Received 6 June 2012; accepted 31 July 2012; published online 29 August 2012. doi:10.1038/mi.2012.82
} 
undergo further maturation and differentiation. T cells expressing $\alpha_{4} \beta_{7}$ integrin bind to the ligand mucosal vascular addressin cell adhesion molecule- 1 on the endothelium of intestinal high endothelial vessels, which facilitates their homing to mucosal effector compartments. $\alpha_{\mathrm{E}} \beta_{7}$ integrin on intraepithelial lymphocytes interacts with ligand E-cadherin on epithelial cells of the small intestine, whereas chemokine CCL25 produced by epithelial cells of the small intestine binds to CCR9 expressed on the majority of lymphocytes of the small intestine. ${ }^{7}$

Lamina propria lymphocytes and intraepithelial lymphocytes are considered effector cells located in the immune-effector sites of the GI tract. Lamina propria lymphocytes are distributed throughout the lamina propria mucosa and are differentiated effector T cells that secrete effector cytokines. ${ }^{7}$ Intraepithelial lymphocytes are located in the basolateral spaces between luminal epithelial cells and beneath tight junctions. Greater than $80 \%$ of intraepithelial lymphocytes are CD8 $+\mathrm{T}$ cells. Furthermore, although $\mathrm{B}$ lymphocytes with a propensity toward IgA production are present to a significant degree in the intestinal mucosal, ${ }^{8} \mathrm{~T}$ cells predominate and have a key role in the adaptive immune response. ${ }^{7}$ It is also noteworthy that there is immunological diversity within the gut. For example, Peyer's patches are especially predominant in the ileum of the small intestine. The jejunum contains mainly effector sites with typically fewer immune-inductive sites, in contrast to the ileum and colon where the reverse applies. ${ }^{9}$

\section{PATHOGENESIS OF HIV INTHE GITRACT}

In the pre-HAART era, diarrhea and other GI disorders would frequently emerge before the development of AIDS. In 1984, Kotler et al. ${ }^{10}$ were the first to describe specific histological abnormalities in the lamina propria of jejunal and rectal mucosa biopsies of $12 \mathrm{HIV}$-infected individuals. Enteropathy was characterized by inflammatory infiltrates of lymphocytes and damage to epithelial layers manifested by villous atrophy, crypt hyperplasia, and villous blunting. These anomalies were noted in the absence of other viral, fungal, or bacterial infections. ${ }^{10}$

Subsequent studies have confirmed these findings and have further characterized the GI aberrations associated with HIV infection. These epithelial anomalies include decreased capacity for regeneration, impaired absorptive ability of GI mucosa, ${ }^{11,12}$ and increased mucosal permeability which can exceed that in HIV-uninfected individuals fivefold. ${ }^{12,13}$ Furthermore, gene expression profiling of GALT reveals dysregulation of genes associated with T-cell homeostasis, growth factor production, and cell cycle mediators. Upregulation of genes associated with apoptosis and necrosis are also observed. ${ }^{14,15}$ GALT is also an anatomical reservoir of HIV, ${ }^{1,2}$ setting a barrier for strategies aimed at HIV eradication.

One of the major reasons for the interest in the ability of HAART to attenuate GI immune damage stems from the fact that disruption of GALT has been shown to correlate with HIV disease progression. ${ }^{3}$ Owing to disrupted integrity of the GI epithelial barrier by HIV, antigens enter blood plasma and stimulate inflammatory cytokine release. This, in turn, promotes systemic immune activation, rendering cells more susceptible to HIV infection and interfering with normal immune function. ${ }^{16}$ Higher plasma lipopolysaccharide (LPS) levels have been detected in individuals with HIVassociated dementia compared with HIV-infected individuals with normal cognitive function. ${ }^{17}$ This association is thought to relate to monocyte activation and entry in the central nervous system via an LPS-mediated process. ${ }^{17}$ However, although associations have been found between increased LPS levels and HIV disease progression, it should be noted that a causative relationship has not been firmly established. ${ }^{3}$

Among the aspects of gut immunity that have been explored in the context of HIV infection, the number and/or percentage of lymphocytes within various areas of the gut that are $\mathrm{CD} 4+\mathrm{T}$ cells has received the most attention. In healthy, HIV-uninfected individuals, $40 \%$ of lymphocytes in GALT are CD $4+$ T cells. ${ }^{4,5,18}$ Several studies have used this value from healthy individuals as a baseline, and have compared values obtained from HIV-infected individuals in order to assess the ability of HAART to facilitate recovery. GI CD4 + T-cell depletion, which is characteristic of all stages of HIV infection, ${ }^{4,5}$ is most marked in effector sites such as the lamina propria but still occurs to a lesser degree in inductive sites such as organized lymphoid tissue. When gut immune reconstitution does occur in the setting of HAART, the majority of $\mathrm{CD} 4+\mathrm{T}$ cells are central memory and transitional memory $\mathrm{T}$ cells and a minor population of cells are effector memory cells. ${ }^{19,20}$ It should be noted, however, that HIV infects many types of cells and there are currently no well-defined criteria for what constitutes good GI immune restoration in HIV-infected individuals. Furthermore, it has been shown that immune reconstitution occurs to a greater extent within immune-inductive sites than within immune-effector sites. ${ }^{21}$ As different studies have examined different regions of the GI tract, it is important to bear in mind these differences as this may account for some of the variability in findings between studies.

\section{DIFFERENCES IN CD4 + T-CELL POPULATIONS BETWEEN PERIPHERAL BLOOD AND GALT}

There are several key differences between CD4 + T-cell populations in peripheral blood and GALT. Notably, peripheral T lymphocytes represent only $2-5 \%$ of total lymphocytes in healthy individuals, whereas $80 \%$ of total body lymphocytes reside in GALT. ${ }^{18,22}$ The percentage of infected cells also differs remarkably between compartments and depends upon the stage of HIV infection. During acute infection, HIV RNA is detectable in $0.01-1 \%$ of peripheral $\mathrm{T}$ cells, compared with $60 \%$ of mucosal memory CD $4+\mathrm{T}$ cells. ${ }^{4,6}$ As reviewed by Mehandru, ${ }^{4,5,9}$ the propensity of the GI tract toward HIV infection relates in part to the fact to the higher percentage of activated memory $\mathrm{T}$ cells expressing CCR5 chemokine receptors located within the gut. Furthermore, as the GI mucosa has continuous exposure to antigen, it is in a proinflammatory state and secretes many cytokines that stimulate the HIV replication. $^{9}$ 


\section{THE EFFECT OF HAART ON CD4 + T-CELL RECOVERY Chronic and advanced infection}

Effect of HAART alone. Interest in delineating the ability of HAART to reverse the deleterious effects of HIV on the GI immune system dates back to the 1990s. In one of the earliest studies, Kotler et al. ${ }^{23}$ noted a modest increase in CD4+ lymphocytes in sigmoid and rectal mucosa of $15 \mathrm{HIV}$-infected individuals 7 days after either initiating or changing to a more effective antiretroviral regimen. Subsequent studies examined the effects of HAART over time periods ranging from 1 month $^{24}$ to 7 years. ${ }^{21}$ These studies have demonstrated wide variation in the degree of CD $4+\mathrm{T}$-cell reconstitution observed in the gut mucosa in response to HAART, ranging from minimal ${ }^{18}$ to near-complete, ${ }^{25}$ reconstitution (Table $\mathbf{1}$ ).

Several more recent studies in the context of chronic HIV infection have demonstrated that HAART is associated with partial GI immune recovery. In a study of eight HIV-infected individuals on HAART for an average of 8.4 years, CD $4+\mathrm{T}$ cells represented $11.3 \%$ of gut lymphocytes. ${ }^{1}$ This was in sharp contrast to other studies involving healthy, HIV-uninfected individuals, where $\sim 40 \%$ of lymphocytes in GALT were CD $4+$ T cells. ${ }^{4,5,18}$ Furthermore, in a study involving five HIV-infected individuals, delayed and incomplete restoration of intestinal CD4 + T cells was observed after 2 years of HAART. CD4+ T-cell proportion preceding HAART was $12 \%$, which increased to only $22 \%$ after this time period. In one individual examined after 5 years of HAART, intestinal CD $4+$ T-cell percentage was only $13 \% .{ }^{18}$ Therefore, despite several years of HAART, reconstitution of gut $\mathrm{CD} 4+\mathrm{T}$ cells is typically incomplete.

Despite less than ideal outcomes in some studies, other studies have demonstrated that significant CD4+ T-cell recovery within the GI tract is, in fact, achievable in some individuals. In one of the largest studies to date, CD4 + T-cell restoration in 14 $\mathrm{HIV}$-infected individuals before and during long-term (5-18 years) HAART was examined. ${ }^{26}$ Eight HIV-infected individuals restored CD $4+\mathrm{T}$-cell percentage in GALT to less than half of the percentage observed in healthy individuals. However, six individuals restored CD $4+\mathrm{T}$-cell percentages to greater than half of that observed in HIV-uninfected controls. A correlation was also observed between the extent of mucosal CD4+ $\mathrm{T}$-cell reconstitution and gut $\mathrm{CD} 4+\mathrm{T}$-cell responses to HIV gag peptides, as measured by interferon- $\gamma$, interleukin (IL)-2, and tumor necrosis factor- $\alpha$ production after $>5$ years of HAART. Therefore, a pivotal finding of this study was that CD4+ $\mathrm{T}$-cell gut reconstitution does not need to be complete in order to observe functional improvement in CD $4+\mathrm{T}_{\text {cell. }}{ }^{26}$

In contrast to several of the aforementioned studies, one study found that near-complete CD4 + T-cell reconstitution was achievable with HAART. ${ }^{25}$ Individuals had commenced therapy a mean of 28 months after receiving a diagnosis of $\mathrm{HIV}$ infection. The mean proportion of CD $4+\mathrm{T}$ cells in the sigmoid colon was significantly higher than that in peripheral blood (56\% vs. $45 \%$, respectively) and did not significantly differ from the proportion of CD $4+$ T cells observed in three HIVnegative controls (56\% vs. 64\%). Furthermore, sigmoid colon CD4 + T cells expressed levels of the activation markers CD69 and HLA-DR similar to those observed in the sigmoid mucosa of HIV-uninfected controls. ${ }^{25}$ Although HAART was not initiated in acute or primary HIV infection, the authors suggested that complete reconstitution may have been observed as individuals had commenced HAART sufficiently early in the course of HIV infection.

Observations that gut CD4 + T-cell reconstitution is incomplete with HAART were followed by attempts to facilitate this process. One such approach included a HAART intensification strategy. This strategy is based on the premise that low-level HIV replication within GALT is hampering complete immune recovery. However, individuals receiving raltegravir in addition to standard HAART for 48 or 96 weeks did not experience an increase in sigmoid CD $4+$ T cells. $^{27}$

HAART in combination with IL-2. Other attempts at facilitating gut CD4 + T-cell recovery, such as IL-2 injections as an adjunctive therapy to HAART, have also been explored. Despite previous findings demonstrating that IL-2 administration can augment peripheral CD $4+\mathrm{T}_{\text {cells }},{ }^{28} \mathrm{IL}-2$ has not proven to be effective in promoting GI CD4 + T-cell reconstitution. In a randomized controlled trial, there were no differences observed in CD4 + T-cell counts in the terminal ileum or colon between 11 HIV-infected individuals who received a median of 7 cycles of IL-2 combined with HAART, compared with 12 individuals who received HAART alone. There was also no change observed in the expression of the proliferation marker Ki67 or in the expression of CD25. ${ }^{29}$ On the basis of these findings, the approach of using adjunctive IL-2 as a means of facilitating GI immune reconstitution has since been abandoned.

Specific T-cell subsets. In addition to examining gut CD4+ T cells, the effect of HAART on specific T-cell subsets has also been explored. This interest stems from recognition of the important roles some of these $\mathrm{T}$-cell subsets have in maintaining GI immune homeostasis. A preferential depletion of Th17 cells in the gut of HIV-infected individuals has been observed. ${ }^{4}$ These IL-17-producing CD4 + T cells have a pivotal role in maintaining the intestinal epithelial barrier ${ }^{30}$ and increase in mucosal tissue in response to HAART. ${ }^{19,26}$ Fewer Th17 cells have been observed in the sigmoid colon in HIV-infected individuals with peripheral CD $4+$ T-cell count $<350$ cells $\mu \mathrm{l}^{-1}$ compared with HIV-uninfected individuals. Evidence that initiation of HAART with peripheral CD4 + T-cell count $>350$ cells $\mu l^{-1}$, rather than $<350$ cells $\mu \mathrm{l}^{-1}$, is associated with greater restoration of sigmoid Th17 cells supports earlier initiation of HAART. ${ }^{19}$

Studies on additional T-cell subsets have included investigations on $\mathrm{T}$ regulatory cells $\left(\mathrm{T}_{\text {regs }}\right)$. Studies from primates have shown that loss of Th17 cells is associated with increases in $\mathrm{T}_{\text {regs }}$. It has been suggested that $T_{\text {regs }}$ have a role in mitigating immune hyperactivation and suppressing immune response to HIV and mucosal pathogens. ${ }^{31}$ In contrast to Th17 cells, mucosal $\mathrm{T}_{\text {regs }}$ are increased in untreated HIV-infected individuals, whereas individuals on HAART have normal levels of these cells. ${ }^{31}$ Given the reciprocal relationship between Th17 cells and $\mathrm{T}_{\text {regs }}$, it has been suggested that the balance of Th17 cells to $\mathrm{T}_{\text {regs }}$ may, in 


\begin{tabular}{|c|c|c|c|c|c|}
\hline Author & $\begin{array}{l}\text { Baseline patient } \\
\text { characteristics/study groups }\end{array}$ & $\begin{array}{l}\text { Number of } \\
\text { subjects }\end{array}$ & $\begin{array}{l}\text { Duration of } \\
\text { HAART at time } \\
\text { of endoscopy }\end{array}$ & Tissue source & Findings \\
\hline $\begin{array}{l}\text { Kotler } \\
\text { et al. }\end{array}$ & 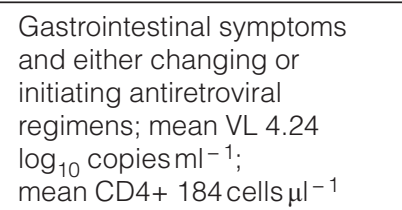 & 15 & 0 and 7 days & $\begin{array}{l}\text { Rectosigmoid } \\
\text { colon }\end{array}$ & $\begin{array}{l}\text { Significant increase in CD } 4+\text { T cells } \\
\text { during therapy ( } 3.02 \text { vs. } 4.49 \text { CD } 4+ \\
\text { T cells/high-power field pre- and } \\
\text { post-therapy, respectively) }\end{array}$ \\
\hline \multirow[t]{2}{*}{$\begin{array}{l}\text { Guadalupe } \\
\text { et al. }{ }^{18}\end{array}$} & $\begin{array}{l}\text { 1-HAART-naive with VL } \\
\text { range } 970->500,000 \\
\text { copies } \mathrm{ml}^{-1} ; \mathrm{CD} 4+\text { range } \\
\text { 8-762 cells } \mu \mathrm{l}^{-1}(n=4) \\
\text { 2-On HAART for >5 } \\
\text { years with VL BLQ; CD4+ } \\
800 \text { cells }\left.\mu\right|^{-1}(n=1)\end{array}$ & 5 & $\begin{array}{c}0,2,3 \text { and } \\
6 \text { months, } \\
1 \text { and } 2 \text { years }\end{array}$ & Jejunum & $\begin{array}{l}\text { Gut CD4 + T-cell proportion increased } \\
\text { following } 2 \text { years of HAART, but not } \\
\text { to levels observed in HIV-uninfected } \\
\text { controls included in the same study: } \\
\text { Patient 120: } 1 \% \rightarrow 16 \% \\
\text { Patient 123: } 2 \% \rightarrow 12 \% \\
\text { Patient 104: } 8 \% \rightarrow 13 \% \\
\text { Patient 101: } 3 \% \rightarrow 22 \%\end{array}$ \\
\hline & & & & & $\begin{array}{l}\text { One individual with } 13 \% \text { CD } 4+\text { T cells } \\
\text { after } 5 \text { years of HAART }\end{array}$ \\
\hline $\begin{array}{l}\text { Macal } \\
\text { et al. }\end{array}$ & $\begin{array}{l}\text { On HAART } \geqslant 5 \text { years } \\
\text { with VL BLQ; CD } 4+\text { range } \\
279-1,185 \text { cells } \mu l^{-1}\end{array}$ & 14 & $\geqslant 5$ years & Jejunum & $\begin{array}{l}\text { Of the individuals on HAART } \geqslant 5 \text { years, } \\
\text { eight individuals restored CD } 4+\% \\
\text { in GALT to greater than half, and six } \\
\text { restored CD } 4+\% \text { in GALT to less than } \\
\text { half of the percentages observed in HIV- } \\
\text { uninfected controls in the same study }\end{array}$ \\
\hline $\begin{array}{l}\text { Sheth } \\
\text { et al. }\end{array}$ & $\begin{array}{l}\text { VL BLQ for mean } 7.4 \text { years; } \\
\text { mean CD4+ percentage } 45 \%\end{array}$ & 23 & $\geqslant 4$ years & Sigmoid colon & $\begin{array}{l}\text { CD4 + T cells represented } 56 \% \text { of } \\
\text { lymphocytes in GALT, which did not } \\
\text { significantly differ from HIV-uninfected } \\
\text { controls included in the same study }\end{array}$ \\
\hline Read et al. ${ }^{29}$ & $\begin{array}{l}\text { Subjects randomized to: } \\
\text { 1-HAART continuation } \\
\text { alone }(n=12) \\
\text { 2-HAART continuation }+ \\
\text { IL- } 2 \times 7 \text { cycles }(n=11)\end{array}$ & 23 & 8 years (mean) & $\begin{array}{l}\text { Terminal ileum } \\
\text { and colon }\end{array}$ & $\begin{array}{l}\text { No difference in CD4 + T-cell proportion } \\
\text { in gut mucosa between HIV-infected } \\
\text { individuals receiving IL-2 in addition } \\
\text { to HAART, vs. HAART alone ( } 33 \% \text { vs. } \\
38 \% \text { in colon and } 16 \% \text { vs. } 30 \% \text { in ter- } \\
\text { minal ileum, respectively); percentages } \\
\text { in both groups lower than in controls } \\
\text { included in the same study (54\% in } \\
\text { colon and } 38 \% \text { in terminal ileum) }\end{array}$ \\
\hline
\end{tabular}

Abbreviations: BLQ, below level of quantification; GALT, gut-associated lymphoid tissue; HAART, highly active antiretroviral therapy; HIV, human immunodeficiency virus; IL-1, interleukin-1; VL, viral load.

fact, be more important than the absolute levels of either one independently. ${ }^{32}$

Peripheral blood CD4 + T-cell expression of gut-homing receptors. In addition to the study of immune T-cell populations within the GI tract, studies on peripheral CD4 + T cells and specifically their expression of gut trafficking molecules have furthered our understanding of the process of gut $\mathrm{CD} 4+\mathrm{T}$-cell reconstitution. ${ }^{20}$ In one study, the proportion of cycling $\mathrm{T}$ cells, the number of $\mathrm{CD} 4+\mathrm{T}$ cells, and the proportion of $\beta 7$-expressing CD4 + T cells were normalized in individuals on HAART for $>5$ years. ${ }^{33}$ In another study, a large proportion of CD $4+\mathrm{T}$ cells expressing gut-homing receptors CCR9 and integrin $\alpha 4 \beta 7$ 
remained in the peripheral circulation in HIV-infected individuals, rather than in jejunal mucosa, despite a median duration of HAART $>5$ years. ${ }^{34}$ The authors of this latter study postulated that this likely occurred because expression of the CCR9 ligand CCL25 was reduced in the small intestines of these individuals. ${ }^{34}$ These studies suggest that CD4+ T-cell populations in the gut are likely maintained by T-cell trafficking to gut mucosa rather than local cellular proliferation..$^{33,34}$

\section{Acute and primary HIV infection}

In the setting of chronic HIV infection, less than optimal gut immune reconstitution, despite prolonged periods of effective HAART, has provided the impetus for exploring the effect of timing of HAART initiation. It has been hypothesized that improved gut immune reconstitution is more likely to occur if HAART is initiated earlier in the course of the disease. The rationale for this hypothesis is that gut immune reconstitution would be facilitated in a microenvironment that has not incurred excessive damage due to chronic inflammatory processes. Unfortunately, the majority of studies examining GALT CD4 + T-cell reconstitution in the context of acute and primary HIV infection also appear to demonstrate partial, rather than complete, immune reconstitution (Table 2). In one of the largest studies, Mehandru et al..$^{21}$ examined the effect of HAART on GI immune reconstitution in 40 individuals with acute HIV infection (HIV seroconversion within 6 months), 18 of whom were examined longitudinally over 3 years with serial biopsies of rectosigmoid mucosa ( 5 individuals were examined at year 1, 9 at year 2, and 4 at year 3 of
HAART). Mean CD4 + T-cell percentages in mucosal tissue were $34.6 \%, 30.8 \%$, and $42.3 \%$ after 1,2 , and 3 years of HAART, respectively. Although these percentages were higher than at baseline (15.7\%), they were still lower than those seen in HIVuninfected individuals (56.4\%). Furthermore, compared with healthy HIV-uninfected controls, CD4 + T-cell reconstitution was complete in immune-inductive sites such as the organized lymphoid tissue, but was only partial in immune-effector sites such as the lamina propria. ${ }^{21}$ Similarly, in another study performed by the same investigators involving $27 \mathrm{HIV}$-infected individuals, 19 of whom had been identified during primary infection, CD4 + T-cell depletion was more significant from immune-effector sites compared with that from immuneinductive sites. Loss of CD4 + T cells in rectosigmoid mucosa persisted in eight individuals who had initiated HAART during primary infection and who had received treatment for up to 5 years. ${ }^{5}$ In contrast, Guadalupe et al. ${ }^{18}$ followed an HIV-infected individual who initiated HAART in primary infection (HIV p24 antigen positive and ELISA negative), and found that gut CD4 + T lymphocyte percentage increased from $8 \%$ at baseline to $40 \%$ after 14 months of HAART, a percentage which has been documented in healthy HIV-uninfected individuals. Therefore, although few studies have been performed to date in the context of acute and primary infection, there is some evidence to suggest that the extent of GI immune reconstitution may be more substantial when HAART is initiated early in the course of infection.

Similar to studies in the context of chronic HIV infection, several studies have also demonstrated that levels of peripheral

Table 2 CD4 + T-cell gastrointestinal immune reconstitution with HAART in acute and primary HIV infection (selected studies)

\begin{tabular}{|c|c|c|c|c|c|}
\hline Author & $\begin{array}{l}\text { Baseline patient } \\
\text { characteristics/ } \\
\text { study groups }\end{array}$ & $\begin{array}{c}\text { Number of } \\
\text { subjects }\end{array}$ & $\begin{array}{l}\text { Duration of } \\
\text { HAART at time } \\
\text { of endoscopy }\end{array}$ & $\begin{array}{l}\text { Tissue } \\
\text { source }\end{array}$ & Findings \\
\hline $\begin{array}{l}\text { Guadalupe } \\
\text { et al. }{ }^{18}\end{array}$ & $\begin{array}{l}\text { VL } 1,076 \text { copies } \mathrm{ml}^{-1} \\
\text { CD4+ count } \\
881 \text { cells }\left.\mu\right|^{-1}\end{array}$ & 1 & $\begin{array}{l}0,4,8, \text { and } \\
14 \text { months }\end{array}$ & Jejunum & $\begin{array}{l}\text { Near-complete restoration of CD } 4+T \text { levels } \\
\text { in gut; CD } 4+\text { T-cell percentage } \sim 8 \% \text { before } \\
\text { HAART and } 40 \% \text { after } 14 \text { months of HAART }\end{array}$ \\
\hline \multirow[t]{2}{*}{$\begin{array}{l}\text { Mehandru } \\
\text { et al. }{ }^{21}\end{array}$} & $\begin{array}{l}\text { Mean peripheral CD4+ } \\
\text { percentage } 41.5 \% \\
\text { mucosal CD4+ } \\
\text { percentage } 19.3 \%\end{array}$ & 40 & $\begin{array}{l}\text { Cross-sectional } \\
\text { group }(n=22): \\
1-7 \text { years } \\
-1 \text { year }(n=7) \\
-1-3 \text { years }(n=7) \\
-3-7 \text { years }(n=8)\end{array}$ & $\begin{array}{l}\text { Rectosigmoid } \\
\text { colon }\end{array}$ & $\begin{array}{l}\text { Percentages of mucosal memory CD } 4+ \\
\text { T cells after HAART were compared with } \\
\text { that in HIV-uninfected controls included in } \\
\text { the same study }(56.4 \%)\end{array}$ \\
\hline & & & $\begin{array}{l}\text { Longitudinal } \\
\text { group }(n=18) \text { : } \\
1 \text { year }(n=5) \\
2 \text { years }(n=9) \\
3 \text { years }(n=4)\end{array}$ & & $\begin{array}{l}\text { Cross-sectional group } \\
\text { Percentages were } 27.8 \% \text { in individuals after } \\
1 \text { year of HAART, } 42.4 \% \text { after } 1-3 \text { years of } \\
\text { HAART, and } 42.5 \% \text { after } 3-7 \text { years of HAART } \\
\text { Longitudinal group } \\
\text { Percentages were } 34.6 \% \text { after } 1 \text { year of } \\
\text { HAART, } 30.8 \% \text { after } 2 \text { years of HAART, and } \\
41.3 \% \text { after } 3 \text { years of HAART }\end{array}$ \\
\hline $\begin{array}{l}\text { Mehandru } \\
\text { et al. } .^{5}\end{array}$ & $\begin{array}{l}\text { Mean VL } 4.7 \log _{10} \\
\text { copies } \mathrm{ml}^{-1} ; \text { mean } \\
\text { CD4+216 cells }\left.\mu\right|^{-1}\end{array}$ & 8 & $\begin{array}{l}6 \text { months }(n=2) \\
1 \text { year }(n=2) \\
2 \text { years }(n=2) \\
3 \text { years }(n=1) \\
5 \text { years }(n=1)\end{array}$ & $\begin{array}{l}\text { Rectosigmoid } \\
\text { colon }\end{array}$ & $\begin{array}{l}\text { Mean CD4+ percentage was } 35 \% \text { of gut } \\
\text { lymphocytes following HAART; this was } \\
\text { significantly lower than levels in HIV-unin- } \\
\text { fected individuals included in the same study } \\
(\sim 55 \%)\end{array}$ \\
\hline
\end{tabular}

Abbreviations: BLQ, below level of quantification; HAART, highly active antiretroviral therapy; HIV, human immunodeficiency virus; VL, viral load. 
CD4 + T lymphocytes with gut homing potential may be linked with GI mucosal CD4 + T-cell reconstitution in acute infection. Profound depletion of circulating $\alpha 4 \beta 7$ Th lymphocytes was observed in 12 individuals with primary HIV infection. ${ }^{35}$ At baseline, median level of lymphocytes expressing $\alpha 4 \beta 7$ was $48 \times 10^{6}$ cells per liter vs. $240 \times 10^{6}$ cells per liter in HIV-uninfected controls. When re-measured at week 24 post-HAART initiation, there was an increase in $\alpha 4 \beta 7 \mathrm{Th}$ lymphocyte level, although recovery was only partial. ${ }^{35}$ As with the studies in the context of chronic infection, it appears that cell trafficking, rather than local cell proliferation, contributes to CD4 + T-cell restoration in GALT following treatment of acute and primary HIV infection. ${ }^{24}$

\section{OTHER ASPECTS OF IMMUNE RECOVERY CD8 + T-cell responses}

Complementing our understanding of $\mathrm{CD} 4+\mathrm{T}$-cell recovery in the gut has been knowledge gained from studies of other immune cell populations within the gut. Given that the activation status of CD8 + T cells in the peripheral blood has been shown to be a strong predictor of HIV disease progression and death, ${ }^{3,36}$ the effect of HAART on CD8 + T cells within the gut is naturally of interest. In untreated, chronic HIV infection, persistent levels of elevated gut CD8 + T cells are observed. ${ }^{37}$ The use of HAART in the context of chronic HIV infection has been associated with reduced levels of CD $8+\mathrm{T}$ cells, including activated CD8 + T cells, in GI mucosa. These CD8 + T cells displayed attenuated responses to HIV antigens, as demonstrated by reduced degranulation and INF- $\gamma$ and tumor necrosis factor- $\alpha$ production upon exposure to HIV peptides. ${ }^{38,39}$ In acute and early HIV infection, lower levels of memory CD8 + T cells in the GI tract correlated with better reconstitution of CD4 + T cells in GALT following HAART initiation. ${ }^{21}$ Furthermore, in individuals who had commenced HAART in primary HIV infection, an increase in CD8 + T cells was observed upon interruption of therapy. This was accompanied by evidence of increased cytolytic response, such as higher levels of granzymes $\mathrm{H}, \mathrm{K}$, and $\mathrm{M}^{40}$

\section{Natural killer cells and $\gamma \delta \mathrm{T}$ cells}

Like CD8 + T cells, natural killer (NK) cells also have a major role in the immune response to HIV. These cells, which participate in the innate immune response, undergo rapid clonal expansion before adaptive immune responses ensue. ${ }^{41}$ The gut contains two distinct subsets of NK cells that are located in either the intraepithelial lymphocytes or within the lamina propria. ${ }^{42}$ In chronic HIV infection, the frequency of both NK subsets are reduced. Interestingly, both subsets were observed to be significantly expanded in individuals on HAART for a median of 4.4 years, despite incomplete recovery in their peripheral CD $4+$ counts. ${ }^{42}$ Sips et al..$^{42}$ have suggested that mucosal NK cell expansion may therefore be an attempt to compensate for compromised peripheral CD4 + T-cell recovery. Mela et al. ${ }^{43}$ also examined the effect of HAART on NK cell reconstitution in the colonic lamina propria. ${ }^{43}$ They found that colonic NK cell depletion mirrored colonic lamina propria CD $4+\mathrm{T}$-cell decline in HIV-infected individuals with detectable peripheral blood viral loads. With suppression of peripheral blood viral loads by HAART, HIV-infected individuals were found to have higher levels of lamina propria NK cells. When compared with levels in HIV-uninfected individuals, HAART was associated with partial recovery of these cells. ${ }^{43}$

Similarly, another important immune cell population that has been examined in the context of HAART-mediated GI immune system recovery are $\gamma \delta$ cells. While peripheral $\gamma \delta$ cells comprise $4 \%$ of peripheral blood $\mathrm{T}$ cells, ${ }^{44}$ they comprise $40 \%$ intraepithelial lymphocytes within the GI mucosa. ${ }^{45}$ In addition to the production of IL-17 and interferon- $\gamma$, they have important roles in neutrophil recruitment during bacterial infection and in tumor surveillance. ${ }^{46} \mathrm{~V} \delta 1$, as opposed to $\mathrm{V} \delta 2$ cells, are implicated in gut homeostasis ${ }^{47}$ and produce less IL-17 in the setting of simian immunodeficiency virus infection. ${ }^{47}$ Furthermore, the degree of $\mathrm{V} \delta 1$ cell increase correlated with the extent of CD4+ T cell decline and thought to be the consequence of chronic immune activation. ${ }^{47}$ Duodenal $\gamma \delta$ intraepithelial lymphocyte levels have also been shown to be elevated in HIV-infected individuals. ${ }^{48}$ Antiretroviral therapy for up to 42 months was found to result in a decrease in $\gamma \delta$ T-cell levels, although they did not return to levels seen in HIV-uninfected individuals. ${ }^{49}$ Given their role in tumor surveillance, it is interesting to speculate whether dysregulation of these cells may have a role in the propensity of HIV-infected individuals toward certain malignancies despite the use of HAART.

\section{Immunoglobulin production}

Coupled with studies on the ability of HAART to restore gut cellular immunity have been investigations into the effect of HAART on humoral immunity. The largest number of plasma cells producing immunoglobulin (Ig)A are contained within the intestinal lamina propria. ${ }^{8}$ Compared with cellular responses, Ig production within the GI tract of $\mathrm{HIV}$-infected individuals has received much less attention, although abnormalities in $\mathrm{B}$ cells and Igs have been well described. ${ }^{50}$ In one study, reductions in numbers of naive $B$ cells and elevations in memory B cells and plasma cells have been seen in the terminal ileum as early as 17 days after acute HIV infection. By day 47 after acquisition, follicular lysis due to B- and T-cell apoptosis and destruction of the follicular dendritic cells networks in the terminal ileum and Peyer's patches were observed. ${ }^{51}$ In HIV-infected individuals, receiving an effective HAART regimen has been associated with normalization of gut IgG1 and IgA levels. ${ }^{52}$

\section{Intestinal epithelial barrier and microbial translocation}

HIV infection has been associated with various anomalies of the intestinal mucosa, such as proliferation of crypt cells in the jejunal lamina propria and a reduction is the surface area of the villi. ${ }^{53}$ However, a critically important aspect of GI immunity relates to the ability of the GI epithelium to function as a barrier. Integrity of the intestinal epithelial barrier is required to prevent translocation of antigenic material from the intestinal lumen into the systemic circulation, whereby it induces chronic immune activation by binding to pattern- 
recognition receptors on immune cells. ${ }^{54}$ Systemic immune activation has received much attention in recent years due to its association with accelerated HIV disease. ${ }^{3}$ Compared with HIV-uninfected controls, HIV-infected individuals have defects in their mucosal barriers, as demonstrated by reduced epithelial resistance, increased mannitol permeability, high levels of epithelial apoptosis, abnormal claudin expression (which promote pore-formation and pore-sealing), reduced mucosal cytokine production, and villous atrophy. ${ }^{55}$ Increased paracellular permeability and disruption in tight junctions in HIV infection may be mediated by increased expression of claudin-2 and SYN1 protein on the intestinal epithelium, culminating in elevated bacterial binding and enhanced internalization into intestinal epithelial cells. ${ }^{56}$

Examination of tissue from simian immunodeficiency virusinfected rhesus macaques has revealed an association between bacterial translocation and reduced integrity of the GI epithelial barrier. In contrast, in sooty mangabeys who are natural hosts of simian immunodeficiency virus, progressive disease did not develop, epithelial breakdown did not occur, and neither increased microbial translocation nor pathological immune activation was detected. ${ }^{54}$ These observations were made in the absence of detectable simian immunodeficiency virus replication in the lamina propria, suggesting that microbial translocation itself may be a contributing factor in chronic immune activation. ${ }^{54}$

In human subjects, HAART has been associated with normalization of some epithelial defects, as determined by impedance spectroscopy and $\left[{ }^{3} \mathrm{H}\right]$ mannitol fluxes in duodenal biopsies. ${ }^{55}$ Several other studies have examined microbial translocation after HAART administration. Brenchley et al. ${ }^{16}$ have observed that HAART decreased plasma LPS levels but did not result in its complete elimination from peripheral blood circulation, and there was no correlation between LPS levels and viral loads. ${ }^{16}$

Many studies have also found incomplete suppression of microbial translocation in individuals despite up to 6 years of HAART. ${ }^{16,57-59}$ A direct correlation was found between plasma levels of LPS and tumor necrosis factor in HAARTtreated individuals, supporting a role for microbial translocation in chronic inflammation. ${ }^{58}$ Along a similar vein, Jiang et al. ${ }^{59}$ found a strong association between CD8 + T-cell activation, compromised CD4 + T-cell restoration and elevated levels of bacterial DNA. Furthermore, although changes in peripheral CD4 + T-cell levels correlated with reductions in microbial translocation, this was not associated with HAARTmediated declines in viral loads. ${ }^{59}$ In another study that quantified HIV DNA in the gut of HAART-treated patients, levels of DNA were correlated with levels of LPS and immune activation, as measured by CD $8+$ CD $38+$ T cells. ${ }^{60}$ Interestingly, Baroncelli et al. ${ }^{61}$ found that LPS levels in patients on HAART with HIV viremia $<2.5$ copies $\mathrm{ml}^{-1}$ were comparable to LPS levels measured in HIV-uninfected subjects. Therefore, in the presence of maximal viral suppression, microbial translocation may actually return to levels found in HIV-uninfected individuals.

\section{Lymphatic tissue architecture}

The orchestration of several immune functions, many of which involve cells discussed above, are dependent upon intact lymphatic tissue architecture. However, the vast majority of HIV replication occurs within $\mathrm{T}$-cell zones of lymph nodes and results in an immune response characterized by significant inflammation and damage to lymphatic tissue architecture. Marked depletion of CD $4+\mathrm{T}$ cells is also observed within lymphatic tissues during HIV infection. ${ }^{62,63}$ Examination of peripheral lymph node architecture and CD $4+\mathrm{T}$ cells in 23 HIV-infected individuals on HAART revealed architectural abnormalities in all samples. ${ }^{63}$ Although peripheral blood CD4 + T-cell reconstitution was observed with HAART for a median of 84 weeks, CD $4+$ T-cell levels in lymphatic tissue were reduced in $89 \%$ of samples, and $39 \%$ had levels of CD $4+$ $\mathrm{T}$ cells that were less than half of the values seen in HIV-uninfected control subjects. ${ }^{63}$ Other studies have also demonstrated significant architectural damage and deposition of collagen in peripheral lymph nodes of HIV-infected subjects despite up to 6 months of HAART. ${ }^{62}$

Discovery of architectural damage and poor peripheral and lymphatic tissue CD4 + T-cell reconstitution, despite HAART, has been the impetus for examination of lymphatic tissue architecture within the GI tract as a potential explanation for incomplete CD4 + T-cell reconstitution within the GI tract. In $\mathrm{HIV}$-infected individuals at different stages of disease, CD4 + Tcell depletion in GALT was correlated with greater rapidity and magnitude of collagen deposition in this compartment, compared with that in peripheral lymph nodes. ${ }^{64}$ In one study, the mean percentage of GALT tissue that stained positive for collagen in HIV-infected individuals was $15.5 \%$ (vs. $4.4 \%$ in HIVuninfected controls) and did not significantly improve after 6 months of HAART. ${ }^{64}$ Peyer's patches contained significantly more collagen than lymph node tissue. Furthermore, there was a negative correlation between the extent of collagen deposition in the T-cell zone of the Peyer's patches and the size of the total CD4 + T-cell population. CD4 + T-cell depletion in GALT was correlated with greater speed and extent of collagen deposition in GALT, compared with peripheral lymph nodes. ${ }^{64}$

\section{SUMMARY AND CONCLUSION}

HAART-mediated suppression of HIV replication may enable epithelial repair, resulting in reduced mucosal permeability and minimization of bacterial translocation. This, in turn, reduces inflammatory responses and attenuates deleterious processes associated with systemic immune activation. ${ }^{3,16}$ However, immune restoration within GALT is typically incomplete and has been attributed to incomplete viral suppression and persisting immune activation.

A large body of literature has examined CD4+ T-cell reconstitution, and fewer studies have examined other aspects of GI immunity such as CD8 + function, NK cell reconstitution, Ig production, integrity of the intestinal epithelial barrier, bacterial translocation and lymphatic tissue architecture. Although there is some inconsistency in the literature and study designs vary considerably, overall HAART seems to support partial GI 
immune recovery. At the present time, a small number of studies suggest that HAART initiated in acute infection may enable an increase in GI CD4 + T-cell count, which significantly exceeds the rise observed when initiated in chronic infection. In chronic disease the extent of damage, possibly due to collagen deposition and architectural distortion, may be sufficiently severe to make return of normal immunological function unlikely. ${ }^{64}$ Furthermore, incomplete recovery of immune function seems to occur regardless of the cell type or aspect of immune function being examined.

\section{FUTURE DIRECTIONS}

Further studies are required to expand our understanding of the processes involved in immune reconstitution in GALT in the context of both acute and chronic infection. Although findings from elite controllers and long-term non-progressors were not discussed in this review, studies of GALT in these individuals have demonstrated differences between these individuals and HIV-infected individuals on HAART. Delineating the mechanisms of immune control at play in these individuals is important for the development of mucosal vaccines, and may help us to further understand the correlations between different aspects of gut immunity and clinical outcomes.

From a therapeutic perspective, limited data exist on the pharmacokinetics and pharmacodynamics of antiretrovirals within GALT. As it has been demonstrated that antiretroviral susceptibility profiles of HIV isolates from the peripheral blood and GALT differ, ${ }^{65,66}$ it would be useful to delineate whether incomplete immune reconstitution within GALT may be due to low levels of drug within this compartment and/or antiretroviral resistance mutations in HIV itself. This understanding is important for the design of future antiretrovirals and other therapies being designed to eliminate HIV reservoirs. The potential of further immune-based therapies to enhance GI immune restoration, such as cytokines other than IL-2, should also be explored. At present, clinical trials are underway examining the ability of IL7 , in conjunction with HAART, to enable GI immune recovery in HIV-infected individuals. ${ }^{67}$ Similarly, it has been suggested that adjunctive anti-inflammatory therapies may attenuate or reverse lymphoid tissue architectural damage and thus may also merit further exploration. ${ }^{62}$ Finally, and perhaps most importantly, there is a need to define more clearly whether GI immune restoration in HIV-infected individuals correlates with a reduction in any clinically significant adverse events. If this is the case, then the degree of gut immune reconstitution required for HIVinfected individuals to achieve protection against these adverse outcomes will also need to be determined.

\section{ACKNOWLEDGMENTS}

J.B.A. is an Ontario HIV Treatment Network Career Scientist. C.T.C. is a Canadian HIV Clinical Trials Network Fellowship recipient. No funds were received for the preparation of this manuscript.

\section{DISCLOSURE}

The authors declared no conflict of interest.

\section{REFERENCES}

1. Chun, T.W. et al. Persistence of HIV in gut-associated lymphoid tissue despite long-term antiretroviral therapy. J. Infect. Dis. 197, 714-720 (2009).

2. Yukl, S. et al. Differences in HIV burden and immune activation within the gut of HIV-positive patients receiving suppressive antiretroviral therapy. J. Infect. Dis. 202, 1553-1561 (2010).

3. Hofer, U. \& Speck, R.F. Disturbance of gut-associated lymphoid tissue is associated with disease progression in chronic HIV infection. Semin. Immunopathol. 31, 257-266 (2009).

4. Brenchley, J.M. et al. CD4+ T cell depletion during all stages of HIV disease occurs predominantly in the gastrointestinal tract. J. Exp. Med. 2004, 749-759 (2004).

5. Mehandru, S. et al. Primary HIV-1 infection is associated with preferentia depletion of CD4+ T lymphocytes from effector sites. J. Exp. Med. 200, 761-770 (2004).

6. Mattapallil, J.J. et al. Massive infection and loss of memory CD4+ T cells in multiple tissues during acute SIV infection. Nature 434, 1093-1097 (2005).

7. Cheroutre, H. \& Madakamutil, L. Acquired and natural memory T cells joining forces at the mucosal front line. Nat. Rev. Immunol. 4, 292-300 (2004).

8. Husband, A.J. \& Gowans, J.L. The origin and antigen-dependent distribution of lgA-containing cells in the intestine. J. Exp. Med. 148, 1146-1160 (1978).

9. Mehandru, S. The gastrointestinal tract in HIV-1: Questions, Answers, and More Questions. Available at http://www.prn.org/index/php/ progression/article/hiv_1_gastrointestinal_galt_267, accessed 24 February 2012).

10. Kotler, D.P. et al. Enteropathy associated with the acquired immunodeficiency syndrome. Ann. Intern. Med. 101, 421-428 (1984).

11. Ullrich, R., Zeitz, M. \& Riecken, E.O. Enteric immunologic abnormalities in human immunodeficiency virus infection. Semin. Liver Dis. 12, 167-174 (1992).

12. Sankaran, S. et al. Rapid onset of intestinal epithelial barrier dysfunction in primary human immunodeficiency virus infection is driven by an imbalance between immune response and mucosal repair and regeneration. J. Virol. 82, 538-545 (2008).

13. Dandekar, S. Pathogenesis of HIV in the gastrointestinal tract. Curr. HIV AIDS Rep. 4, 10-15 (2007).

14. George, M.D., Reay, E., Sankaran, S. \& Dandekar, S. Early antiretroviral therapy for simian immunodeficiency virus infection leads to mucosal $\mathrm{CD} 4+\mathrm{T}$ cell restoration and enhanced gene expression regulating mucosal repair and regeneration. J. Virol. 79, 2709-2729 (2005).

15. Sankaran, S. et al. Gut mucosal T cell responses and gene expression correlate with protection against disease in long-term HIV-1-infected nonprogressors. Proc. Natl. Acad. Sci. USA 102, 9860-9856 (2005)

16. Brenchley, J.M. et al. Microbial translocation is a cause of systemic immune activation in chronic HIV infection. Nat. Med. 12, 1365-1371 (2008).

17. Acunata, P. et al. Microbial translocation is associated with increased monocyte activation and dementia in AIDS patients. PLOS ONE 3, e2516. doi:10.1371/journal.pone.0002516 (2008).

18. Guadalupe, M. et al. Severe CD4+ T-cell depletion in gut lymphoid tissue during primary human immunodeficiency virus type 1 infection and substantial delay in restoration following highly active antiretroviral therapy. J. Virol. 77, 11708-11717 (2003).

19. Chege, D. et al. Sigmoid Th17 populations, the HIV latent reservoir, and microbial translocation in men on long-term antiretroviral therapy. AIDS 25, 741-749 (2010).

20. Guadalupe, M. et al. Viral suppression and immune restoration in the gastrointestinal mucosa of human immunodeficiency virus type-1 infected patients initiating therapy during primary or chronic infection. J. Virol. 80, 8236-8247 (2006).

21. Mehandru, S. et al. Lack of mucosal immune reconstitution during prolonged treatment of acute and early HIV-1 infection. PLoS Med. 3, e484 (2006).

22. Mowat, A. \& Viney, J. The anatomical basis of intestinal immunity. Immunol. Rev. 156, 145-166 (1997).

23. Kotler, D.P. et al. Effect of combination antiretroviral therapy upon rectal mucosal HIV RNA burden and mononuclear cell apoptosis. AIDS 12, 597-604 (1998). 
24. Talal, A.H. et al. Virologic and immunologic effect of antiretroviral therapy on HIV-1 in gut-associated lymphoid tissue. J. Acquir. Immune Defic. Syndr. 26, 1-7 (2001).

25. Sheth, P.M. et al. Immune reconstitution in the sigmoid colon after longterm HIV therapy. Mucosal Immunol. 1, 382-388 (2008).

26. Macal, M. et al. Effective CD4+ T-cell restoration in gut-associated lymphoid tissue of HIV-infected patients is associated with enhanced Th17 cells and polyfunctional HIV-specific T-cell responses. Mucosal Immunol. 1, 475-488 (2008).

27. Chege, D. et al. Effect of raltegravir intensification on HIV proviral DNA in the blood and gut mucosa of men on long-term therapy: a randomized control trial. AIDS 26, 167-174 (2012).

28. Kovacs, J.A. et al. Controlled trial of interleukin-2 infusions on patients infected with the human immunodeficiency virus. N. Engl. J. Med. 335, 1350-1356 (1996).

29. Read, S.W. et al. The effect of intermittent IL-2 therapy on CD4T cells in the gut in HIV-1-infected patients. J. Acquir. Immune Defic. Syndr. 56, 340-343 (2006).

30. Dandekar, S., George, M.D. \& Baumler, A.J. Th17 cells, HIV and the gut mucosal barrier. Curr. Opin. HIV AIDS 5, 173-178 (2010).

31. Epple, H.J. et al. Mucosal but not peripheral FOXP3+ regulatory T cells are highly increased in untreated HIV infection and normalize after suppressive HAART. Blood 108, 3072-3078 (2006).

32. Kanwar, B., Favre, D. \& McCune, J.M. Th17 and regulatory T cells: implications for AIDS pathogenesis. Curr. Opin. HIV AIDS 5, 151-157 (2010).

33. Ciccone, E.J. et al. Cycling of gut mucosal CD4+ T cells decreases after prolonged anti-retroviral therapy and is associated with plasma LPS levels. Mucosal Immunol. 3, 172-181 (2010).

34. Mavigner, M. et al. Altered CD4+ T cell homing to the gut impairs mucosal reconstitution in treated HIV-infected individuals. J. Clin. Invest. 122, 62-69 (2012).

35. Krzysiek, R. et al. Preferential and persistent depletion of CCD5+ T-helper lymphocytes with nonlymphoid homing potential despite early treatment of primary HIV infection. Blood 98, 3169-3171 (2001).

36. Liu, Z., Cumberland, W.G., Hultin, L.E., Prince, H.E., Detels, R. \& Giorgi, J.V. Elevated CD38 antigen expression on CD8+ T cells is a stronger marker for the risk of chronic HIV disease progression to AIDS and death in the Multicenter AIDS Cohort Study than CD4+ cell count, soluble immune activation markers, or combinations of HLA-DR and CD38 expression. J. Acquir. Immune Defic. Syndr. Hum. Retrovirol. 16, 83-92 (1997).

37. Schacklett, B.L., Cox, C.A., Sandberg, J.K., Stollman, N.H., Jacobson, M.A. \& Nixon, D.F. Trafficking of human immunodeficiency virus type 1 -specific CD8+ T cells to gut-associated lymphoid tissue during chronic infection. J. Virol. 77, 5621-5631 (2003).

38. Critchfield, J.W. et al. Multifunctional human immunodeficiency virus (HIV) Gag-specific CD8+ T-cell responses in rectal mucosa and peripheral blood mononuclear cells during chronic HIV type 1 infection. J. Virol. 81, 5460-5471 (2007)

39. Critchfield, J.W. et al. Magnitude and complexity of rectal mucosa HIV-1specific CD8+ T cell responses during chronic infection reflect clinical status. PLOS ONE 3, e3577 (2008).

40. Lerner, P. et al. The gut mucosal viral reservoir in HIV-infected patients is not the major source of rebound plasma viremia following interruption of highly active antiretroviral therapy. J. Virol. 85, 4774-4782 (2011).

41. Alter, G. et al. Evolution of innate and adaptive effector cell functions during acute HIV-1 infection. J. Infect. Dis. 195, 1452-1460 (2007).

42. Sips, M. et al. Altered distribution of mucosal NK cells during HIV infection. Mucosal Immunol. 5, 30-40 (2012).

43. Mela, C.M. et al. Depletion of natural killer cells in the colonic lamina propria of viraemic HIV-1-infected individuals. AIDS 21, 217-2182 (2007).

44. Bukowski, J.F., Morita, C.T. \& Brenner, M.B. Human gamma delta T cells recognize alkylamines derived microbes, edible plants, and tea: implications for innate immunity. Immunity. 11, 57-65 (1999).

45. Kagnoff, M.F. Current concepts in mucosal immunity. III Ontogeny and function of gamma delta T cells in the intestine. Am. J. Physiol. 274, G455-G458 (1998).
46. Shibata, K., Yamada, H., Hara, H., Kishihara, K. \& Yoshikai, Y. Resident Vdelta1 + gammadelta T cells control early infiltration of neutrophils after Escherichia coli infection via IL-17 production. J. Immunol. 178, 4466-4472 (2007).

47. Harris, L.D. et al. Mechanisms underlying $\gamma \delta$ T-cell subset perturbations in SIV-infected Asian rhesus macaques. Blood 116, 4148-4157 (2010).

48. Nilssen, D.E. et al. Intraepithelial $\gamma / \delta$ T cells in duodenal mucosa are related to the immune state and survival time in AIDS. J. Virol. 70, 3545-3550 (1996).

49. Nilssen, D.E. \& Brandtzaeg, P. Intraepithelial $\gamma \delta$ T cells remain increased in the duodenum of AIDS patients despite antiretroviral treatment. PLOS ONE 7, e29066 (2012).

50. Eriksson, K., Hagberg, L., Norkrans, G., Holmgren, J. \& Czerkinsky, C. Virus-specific antibody production and polyclonal B-cell activation in the intestinal mucosa of HIV-infected individuals. AIDS 9, 695-700 (1995).

51. Levesque, M.C. et al. Polyclonal B cell differentiation and loss of gastrointestinal tract germinal centers in the earliest stages of HIV-1 infection. PLoS Med. 6, e1000107 (2009).

52. Nilssen, D.E. et al. Intestinal B cell hyperactivity in AIDS is controlled by highly active antiretroviral therapy. Gut 53, 487-493 (2003).

53. Batman, P.A. et al. HIV enteropathy: comparative morphometry of the jejunal mucosa of HIV infected patients resident in the United Kingdom and Uganda. Gut 43, 350-355 (1998).

54. Estes, J.D. et al. Damaged intestinal epithelial integrity linked to microbial translocation in pathogenic simian immunodeficiency virus infections. PLoS Pathog. 6, e1001052 (2010).

55. Epple, H.J. et al. Impairment of the intestinal barrier is evidence in untreated but absent in suppressively treated HIV-infected patients. Gut 58, 220-227 (2009).

56. Smith, A.J., Schacker, T.W., Reilly, C.S. \& Haase, A.T. A role for syndecan-1 and claudin-2 in microbial translocation during HIV-1 infection. J. Acquir. Immune Defic. Syndr. 55, 306-315 (2010).

57. Ellis, C.L. et al. Molecular characterization of stool microbiota in HIV-infected subjects by panbacterial and order-level $16 \mathrm{~S}$ ribosomal DNA (rDNA) quantification and correlations with immune activation. J. Acquir. Immune Defic. Syndr. 57, 363-370 (2011).

58. Cassol, E. et al. Persistent microbial translocation and immune activation in HIV-1-infected South Africans receiving combination antiretroviral therapy. J. Infect. Dis. 202, 723-733 (2010).

59. Jiang, W. et al. Plasma levels of bacterial DNA correlate with immune activation and the magnitude of immune restoration in persons with antiretroviral-treated HIV infection. J. Infect. Dis. 199, 1177-1185 (2009).

60. d'Ettore, G. et al. HIV persistence in the gut mucosa of HIV-infected subjects undergoing antiretroviral therapy correlates with immune activation and increased levels of LPS. Curr. HIV Res. 9, 148-153 (2011).

61. Baroncelli, S. et al. Microbial translocation is associated with residual viral replication in HAART-treated HIV+ subjects with $<50$ copies/ml HIV-1 RNA. J. Clin. Virol. 46, 367-370 (2009).

62. Schacker, T.W. et al. Collagen deposition in HIV-1 infected lymphatic tissues and T cell homeostasis. J. Clin. Invest. 110, 1133-1139 (2002).

63. Schacker, T. et al. Persistent abnormalities in lymphoid tissues in human immunodeficiency virus-infected patients successfully treated with highly active antitretroviral therapy. J. Infect. Dis. 186, 1092-1097 (2002).

64. Estes, J.D., Haase, A.T. \& Schacker, T.W. The role of collagen deposition in depleting CD4+ T cells and limiting reconstitution in HIV-1 and SIV infections through damage to the secondary lymphoid organ niche. Semin. Immunol. 20, 181-186 (2008).

65. Van Marle, G., Church, D.L., Nunweiler, K.D., Cannon, K., Wainberg, M.A. \& Gill, M.J. Higher levels of zidovudine resistant HIV in the colon compared to blood and other gastrointestinal compartments in HIV infection. Retrovirol 7, 74 (2010).

66. Van Marle, G., Gill, M.J., Kolodka, D., McManus, L., Grant, T. \& Church, D.L. Compartmentalization of gut viral reservoir in HIV-1 infected patients. Retrovirol 4, 87 (2007).

67. Sereti, I. et al. Gut mucosa T lymphocyte restoration in chronically HIV+ patients treated with recombinant Interleukin-7. 19th Conference on Retroviruses and Opportunistic Infections (CROI) (abstract no. 19) (2012). 